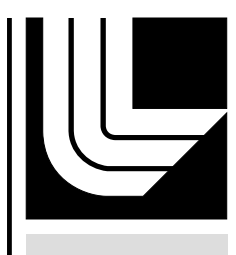

LAW RENCE LIVERMORE N A TIO N A L LABORATORY

Outgassing Studies of Foams for the W80 LEP

Cindy Alviso, Chris Harvey, Andrew Vance

December 1, 2005 
This document was prepared as an account of work sponsored by an agency of the United States Government. Neither the United States Government nor the University of California nor any of their employees, makes any warranty, express or implied, or assumes any legal liability or responsibility for the accuracy, completeness, or usefulness of any information, apparatus, product, or process disclosed, or represents that its use would not infringe privately owned rights. Reference herein to any specific commercial product, process, or service by trade name, trademark, manufacturer, or otherwise, does not necessarily constitute or imply its endorsement, recommendation, or favoring by the United States Government or the University of California. The views and opinions of authors expressed herein do not necessarily state or reflect those of the United States Government or the University of California, and shall not be used for advertising or product endorsement purposes.

This work was performed under the auspices of the U.S. Department of Energy by University of California, Lawrence Livermore National Laboratory under Contract W-7405-Eng-48. 


\title{
Outgassing Studies of Foams for the W80 LEP (FY05)
}

\author{
Cindy Alviso, Chris Harvey \& Andrew Vance \\ Chemistry \& Materials Science
}

\section{Introduction}

Removable epoxy foam (REF) is a novel material developed by researchers at Sandia National Laboratories to simplify the removal of encapsulants from electronic components [McElhanon, et al., Journal of Applied Polymer Science, 2002, 85, 14961502]. The material is based on a resin that includes a thermally reversible chemical bond. When the material is heated at relatively mild temperatures $\left(\sim 50-90^{\circ} \mathrm{C}\right)$ in the presence of appropriate solvents, the reversible bonds are broken, and the material is easily rinsed away. In order to ease the removal of the encapsulant for surveillance purposes, it was proposed to use REF in the W80 LEP in place of the polyurethane TDI (toluene diisocyanate), which is being phased out at the Kansas City Plant due to toxicity concerns. Colleagues at Sandia noted that REF exhibited especially high outgassing of the liquid fluorinert, FC-72, which is used at a level of $5 \mathrm{wt} \%$ as the blowing agent in the foaming process. After obtaining a sample of the material from Sandia, headspace solid phase microextraction gas chromatography-mass spectrometry (SPME GC/MS) measurements were performed. These measurements revealed significant outgassing of fluorinert as well as other solvents and siloxanes [Memo, Vance, 3/3/05 \& Vance, Foam PRT presentation UCRL-PRES-212462]. This report is intended to summarize foam outgassing studies performed at LLNL in support of the W80 LEP.

\section{Results \& Discussion}

Initial screening of REF by headspace SPME GC/MS showed significant outgassing from the material. For comparison, samples of other current or potential stockpile foams were obtained, and their outgassing signatures were collected. Even at room temperature, where other foams showed very low outgassing, REF outgassing was unusually high. For comparison with other foams, data collected from samples equilibrated at $70^{\circ} \mathrm{C}$ will be shown in this report. Chromatograms are presented in the 
appendix. Fig. 1 shows the gas chromatogram from the headspace SPME sampling of an empty SPME vial. The y-axis was scaled to $2.5 \times 10^{7}$, and all subsequent chromatograms are at the same scale for comparison of relative outgassing levels between the different foams.

For headspace sampling of foams, samples of approximately 100-200 mg were placed in $20 \mathrm{~mL}$ SPME vials, purged in a nitrogen glove box, then capped prior to equilibration at room temperature or $70^{\circ} \mathrm{C}$ for 3 days. Headspace SPME sampling was performed by a CombiPAL robotic sampler, assuring consistent sampling conditions. Fig. 2 shows the gas chromatogram of the optimized REF formulation provided by Sandia/NM. In addition to fluorinert, other solvents observed in the headspace included ethanol, 1-propanol, isopropanol, and methyl ethyl ketone (MEK). Numerous siloxanes were also present. To separate the outgassing contributions of the resin, surfactant, and blowing agent, headspace SPME GC/MS analysis was conducted on Removable Syntactic Foam (RSF), which is made from the same resin as REF but does not use the fluorinert blowing agent or the DC-193 siloxane surfactant. Concurrent sampling of DC193 showed that most of the siloxanes observed in REF originated from the DC-193, which is used in $8 \mathrm{wt} \%$ in the foam formulation. Fig. 3 shows the gas chromatogram from the headspace sampling of DC-193. This analysis showed that the isopropanol observed in REF was introduced by the DC-193 along with the siloxanes.

Three polyurethane foams were characterized by headspace SPME GC/MS for comparison to REF. These were PMDI, TufFoam, and TDI. PMDI has been used in the stockpile while TufFoam is a newer formulation developed at Sandia/CA. TDI was used as the encapsulant blown foam in the W80-0/1. Fig. 4 shows the headspace signature of TDI after heating for 3 days. Its principal outgassing components are xylenes. These hydrocarbons have been observed at low levels in actual weapon headspace samples. PMDI exhibited outgassing levels qualitatively similar to TDI. As shown in Fig. 5, the main outgassing component is acetone. TufFoam exhibited similar low outgassing levels as seen in Fig. 6 where acetone and two siloxanes were detected.

The preliminary findings of these outgassing studies were presented in a memo dated 3/3/05. Shortly thereafter, REF was subjected to further scrutiny, and it was determined that its formulation could not be changed to improve its outgassing 
characteristics. Sandia formed a Product Realization Team (the Foam PRT) to evaluate possible replacements for REF. After the formal rejection of REF as the blown foam encapsulant for the W80-3, PMDI was selected as the replacement material with TufFoam as the backup foam. With the exception of easy removal, PMDI met all the requirements for the blown foam encapsulant.

The Foam PRT also reevaluated the choice of RSF as the high voltage encapsulant, and it was determined that Epon828/CTBN/DEA/GMB would replace RSF, while RSF remained the backup material. The Epon828 formulation has a history of reliability and has a very low outgassing signature, as seen in Fig. 7. RSF, as originally formulated, contained a higher than desirable level of siloxanes and solvents that were present as starting material and processing impurities (Fig. 8). As a result of outgassing analyses carried out at LLNL, KCP evaluated their process and added a simple purification step that brought the level of volatiles in the RSF to less than $1 \mathrm{wt} \%$. The outgassing signature of the purified material is shown in Fig. 9.

\section{Conclusions}

After headspace SPME sampling revealed an unusually high outgassing signature for REF, the material was ultimately rejected in favor of the polyurethane PMDI. The immediate impact of a series of simple and rapid outgassing analyses carried out in support of the W80 LEP highlight the importance of considering all aspects of a material's behavior early in the selection process. While factors such as mechanical properties and ease of processing are important, outgassing characteristics must also be taken into account. Whenever possible, materials with the lowest outgassing signatures should be chosen to minimize possible compatibility issues and maintain a clean internal atmosphere over the life of the weapon. In addition, as shown in the case of RSF, analysis of volatile organic outgassing products may also be utilized during the development process to improve the purity of the final product.

\section{Experimental}

The foam samples (100-200 mg) were sealed under nitrogen in $20 \mathrm{~mL}$ SPME vials followed by equilibration for 72 hours at room temperature or at $70^{\circ} \mathrm{C}$. Samples are 
analyzed by SPME GC/MS using an automated system under the following conditions: $75 \mu \mathrm{m}$ Carboxen-PDMS SPME fiber, conditioned for $20 \mathrm{~min}$ at $280^{\circ} \mathrm{C}$; headspace sampled at $50^{\circ} \mathrm{C}$ for $20 \mathrm{~min}$ and injected into the GC for $1 \mathrm{~min}$ at $250^{\circ} \mathrm{C}$. The Agilent 6890 GC is set for splitless injection, purge @ 0.5 min, using a Restek RTX5-MS column (30 m, $0.25 \mathrm{~mm}$ ID, $0.25 \mu \mathrm{m}$ film) with a $1.0 \mathrm{~mL} / \mathrm{min}$ constant flow of helium. The 20 min run has the following temperature profile: $40^{\circ} \mathrm{C} / 2 \mathrm{~min}, 15^{\circ} \mathrm{C} / \mathrm{min}$ to $300^{\circ} \mathrm{C}$, hold 0.67 min. An Agilent 5973 mass spectrometer scans the mass range from 20-450 at a rate of 1.75 scans/sec with a filament delay of zero (in order to detect highly volatile analytes such as fluorinert). 


\section{Appendix}

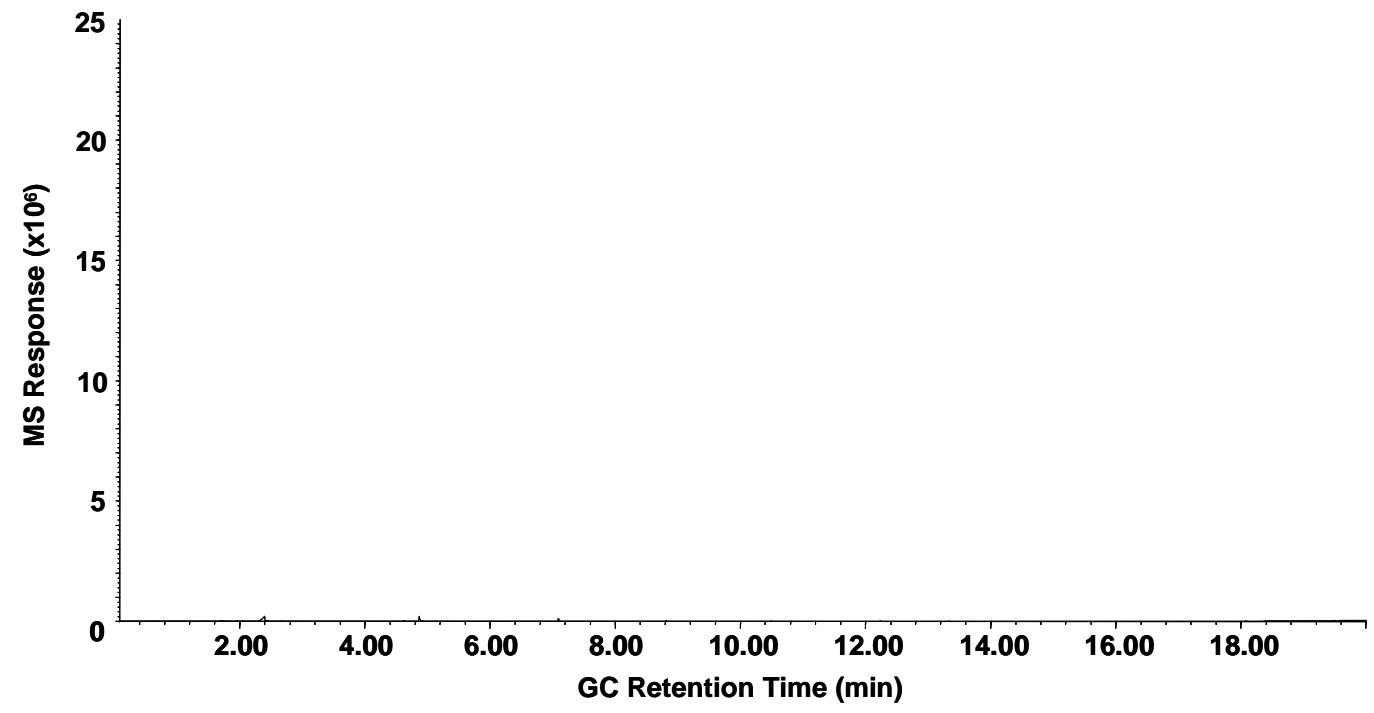

Fig. 1. Gas chromatogram of empty vial after 3 days at $70^{\circ} \mathrm{C}$. 


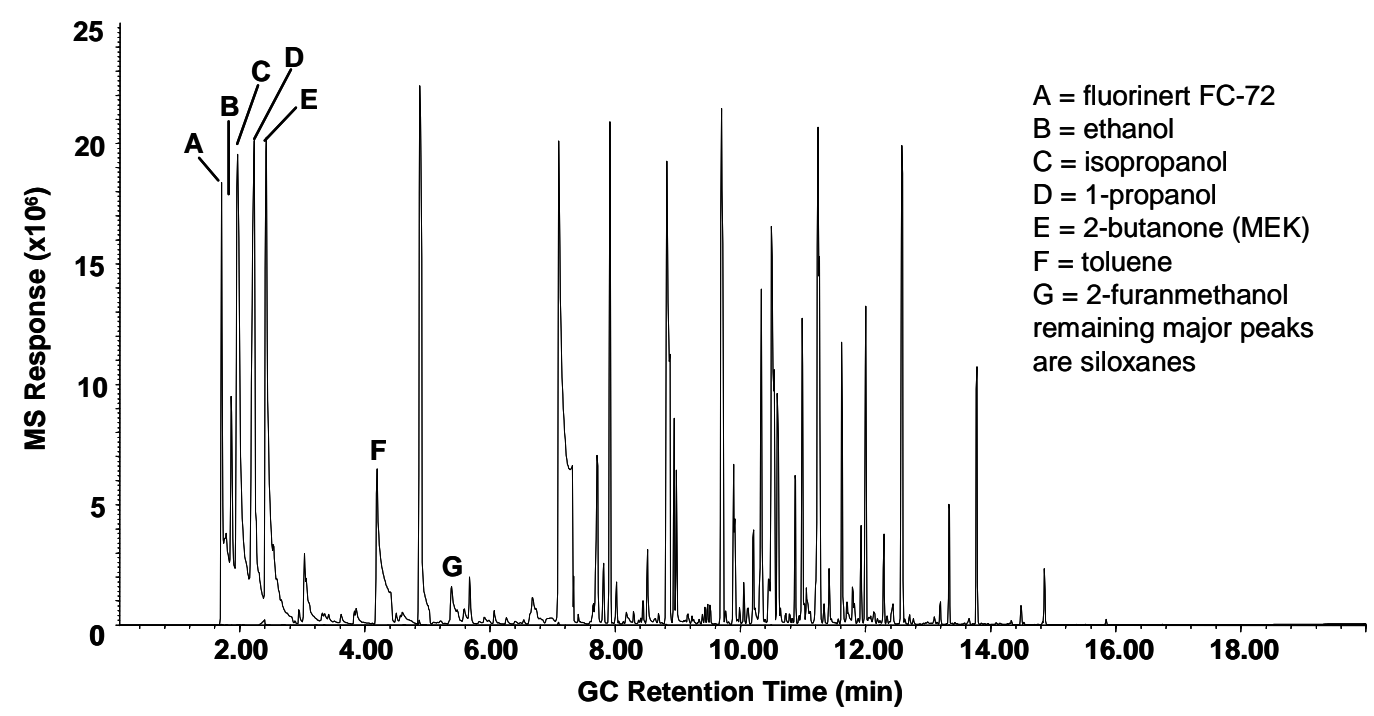

Fig. 2. Gas chromatogram of REF headspace after 3 days at $70^{\circ} \mathrm{C}$.

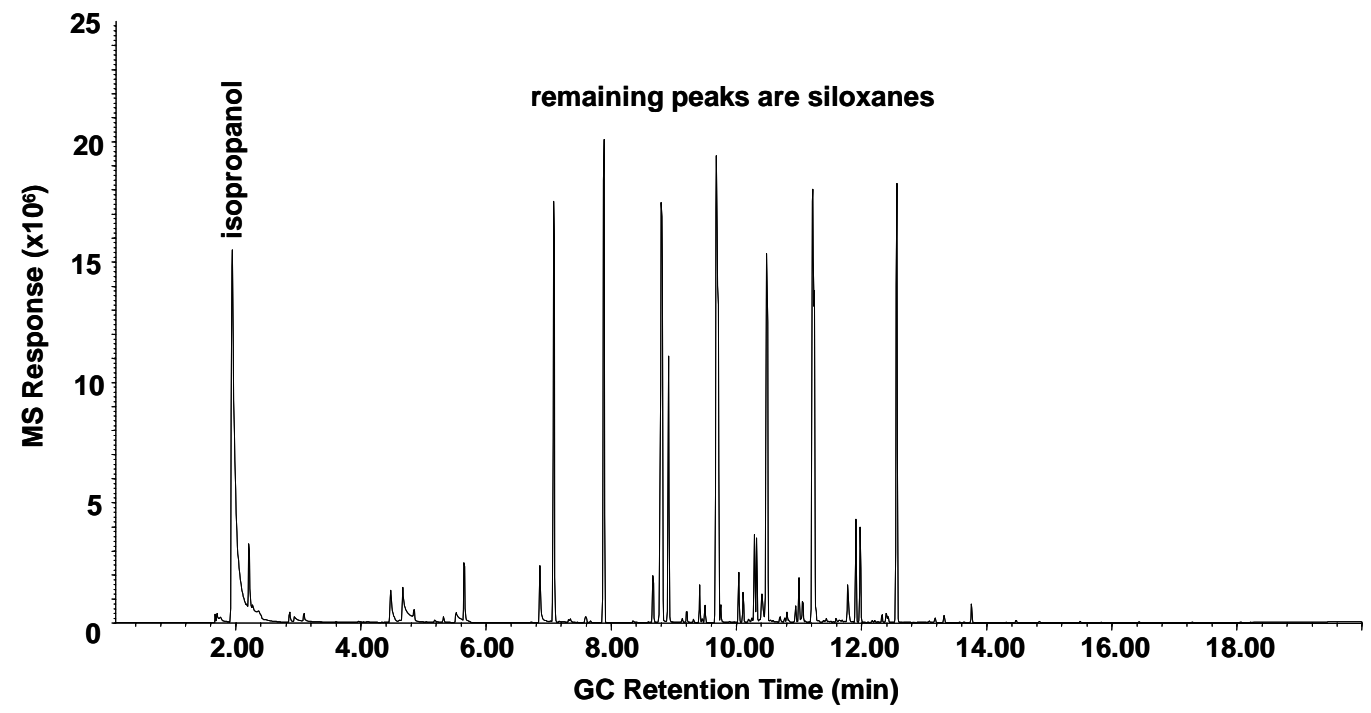

Fig. 3. Gas chromatogram of DC-193 headspace. 


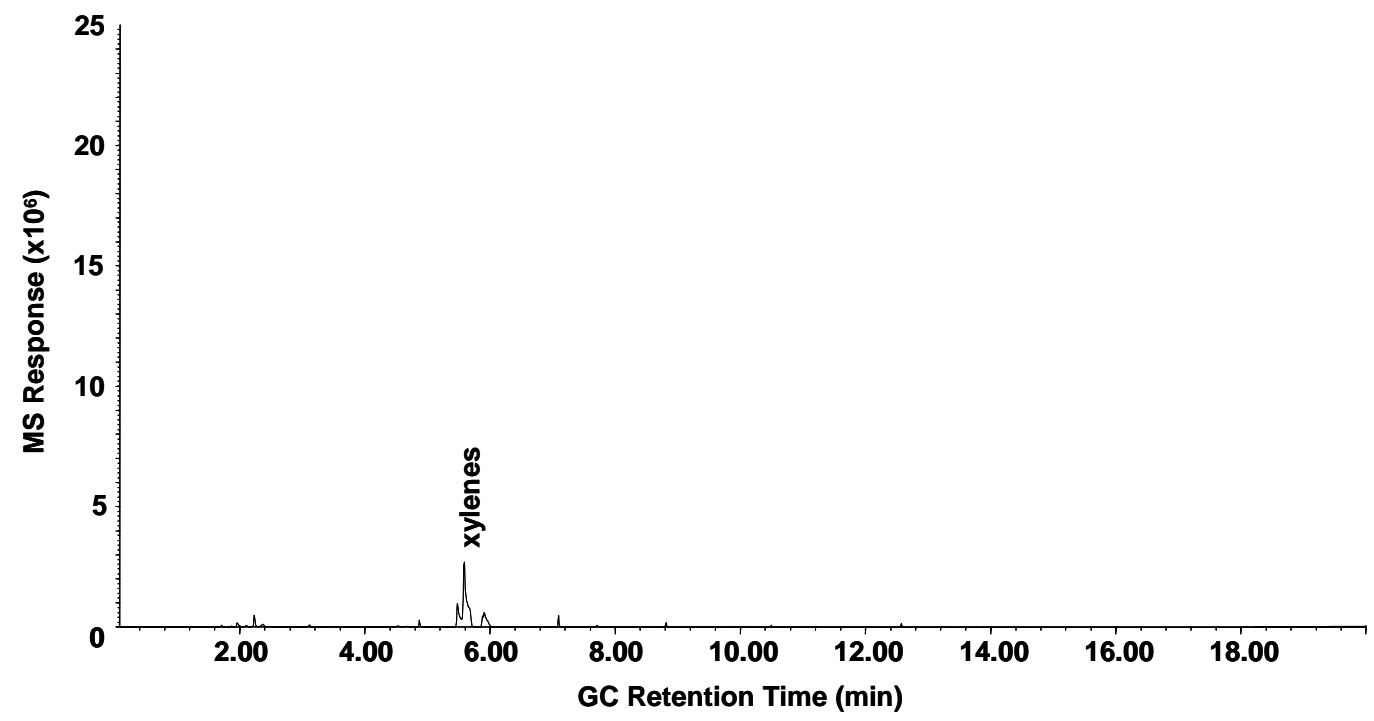

Fig. 4. Gas chromatogram of TDI headspace after 3 days at $70^{\circ} \mathrm{C}$.

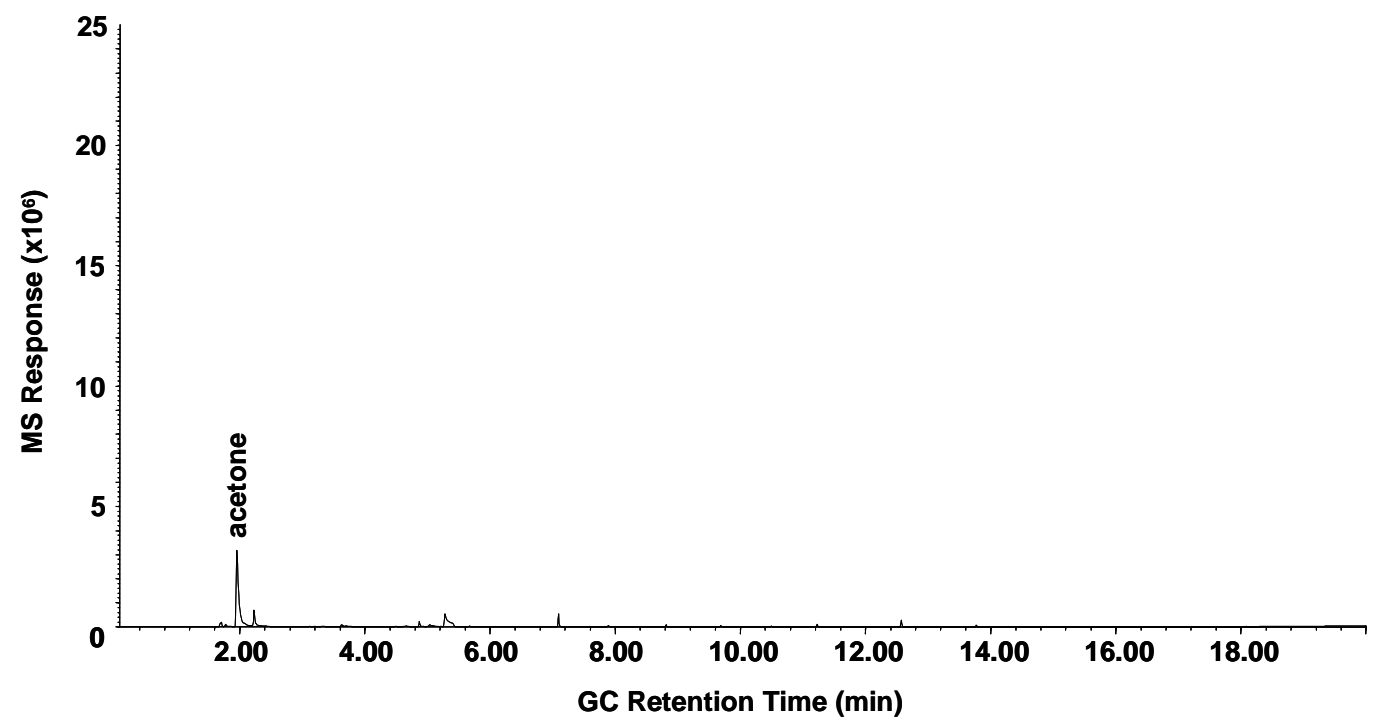

Fig. 5. Gas chromatogram of PMDI headspace after 3 days at $70^{\circ} \mathrm{C}$. 


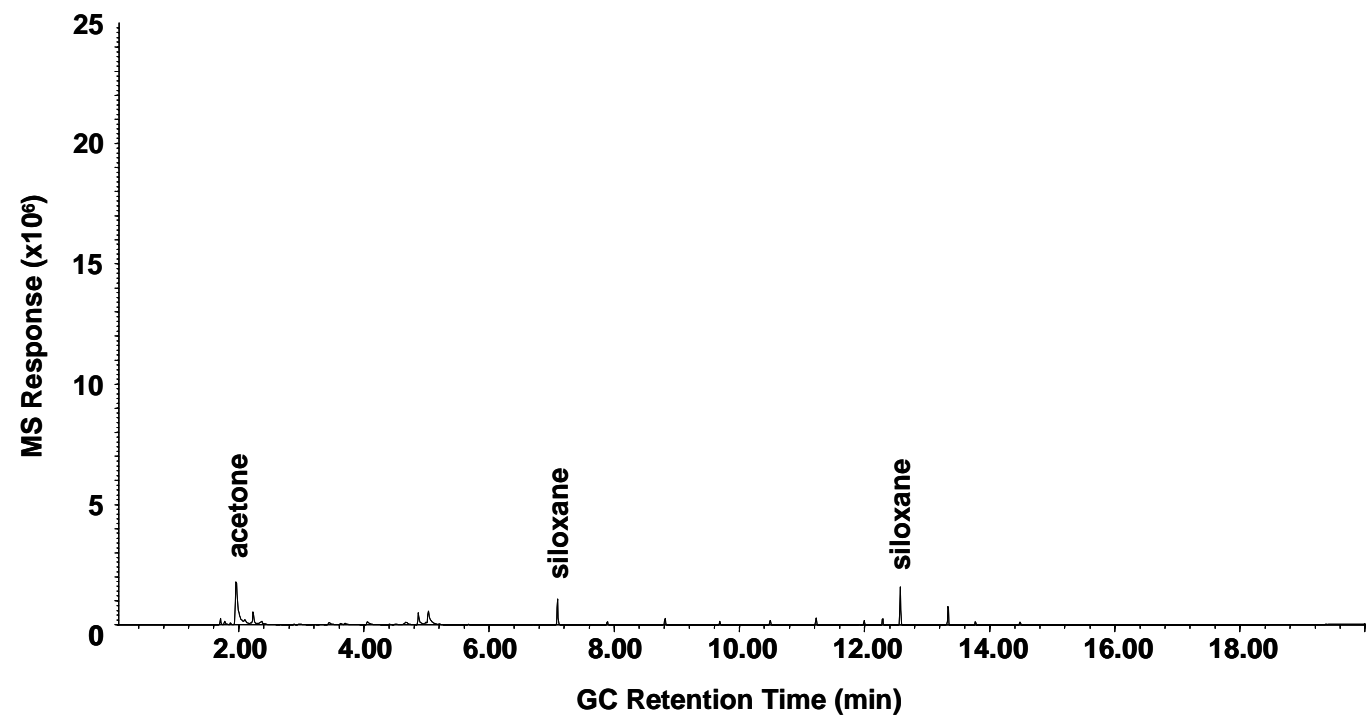

Fig. 6. Gas chromatogram of TufFoam headspace after 3 days at $70^{\circ} \mathrm{C}$.

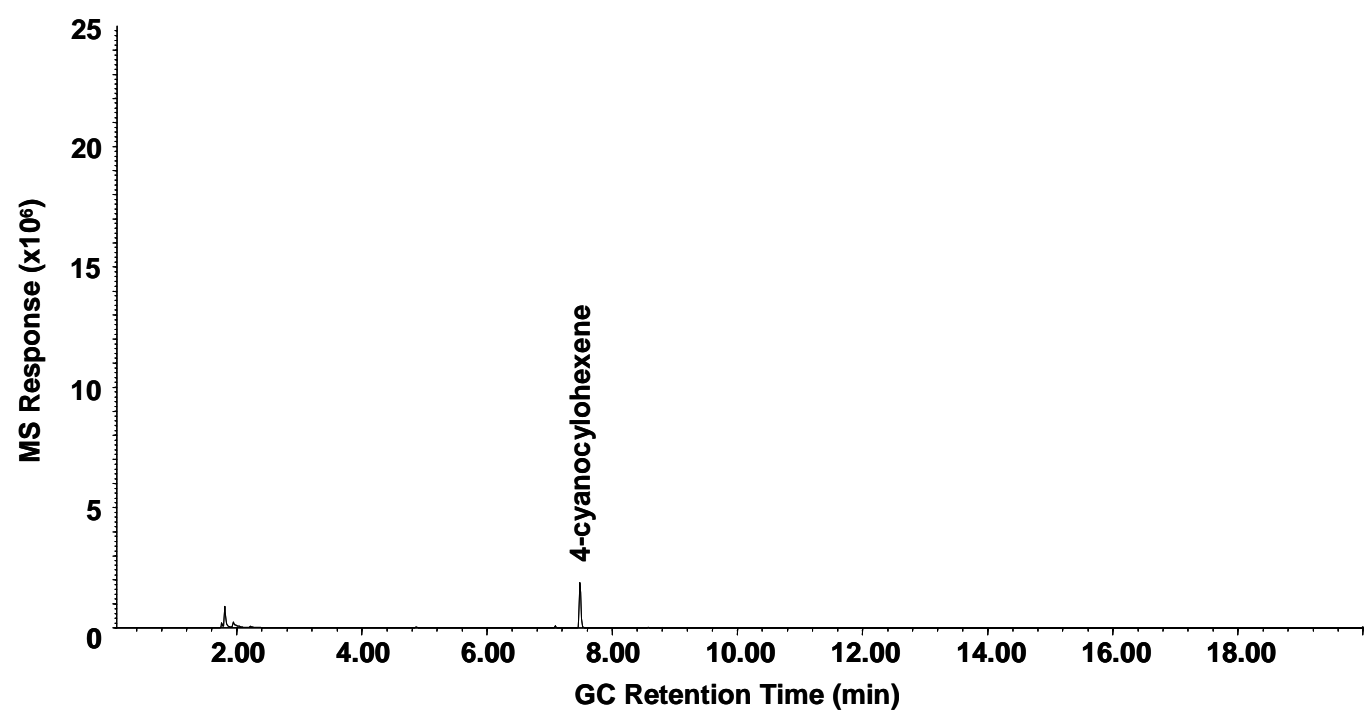

Fig. 7. Gas chromatogram of Epon828/CTBN/DEA/GMB headspace after 3 days at $70^{\circ} \mathrm{C}$. 


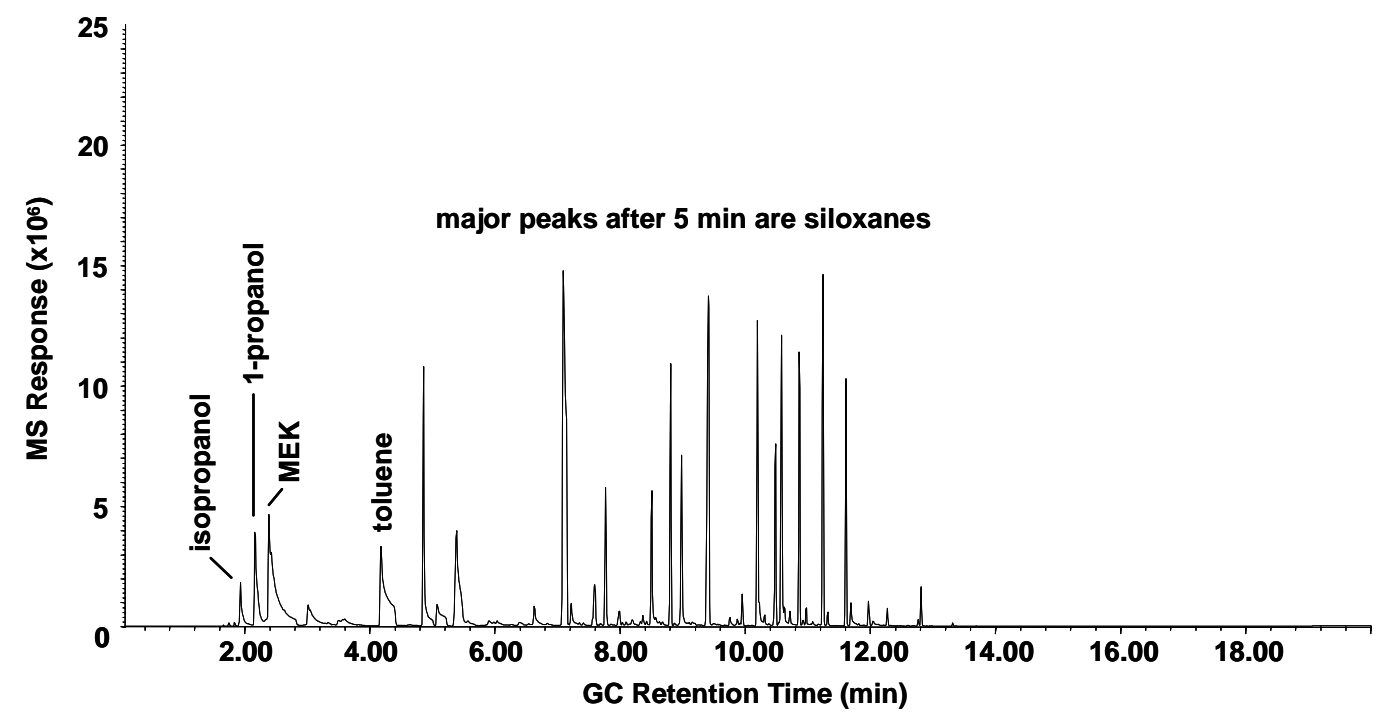

Fig. 8. Gas chromatogram of RSF (before resin purification) headspace after 3 days at $70^{\circ} \mathrm{C}$.

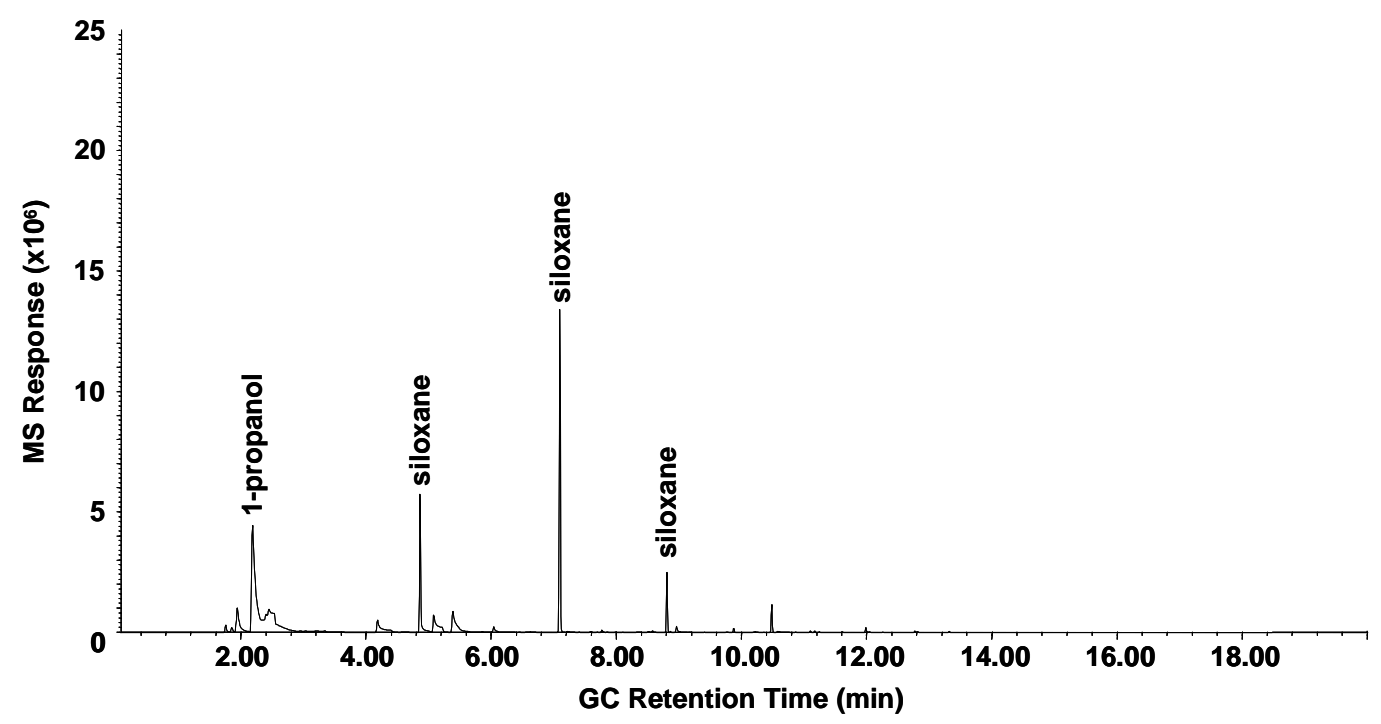

Fig. 9. Gas chromatogram of RSF (after resin purification) headspace after 3 days at $70^{\circ} \mathrm{C}$. 